\title{
Negotiating the Social Organization of School Library Work
}

\author{
Jennifer Crispin \\ Assistant Teaching Professor \\ University of Missouri \\ USA
}

\begin{abstract}
I investigated how school library work is socially organized and how that social organization affects cooperation with teachers and others in the school. The research uses the institutional ethnography frame of inquiry, providing a way of looking at how the role and function of the school librarian/ school media specialist is socially-organized and institutionally-oriented. The social organization was apparent in the categories of collaboration, technology, and access. A better understanding of how library work is socially organized will help working librarians understand how to negotiate their workplace more effectively. An understanding of how to examine the social organization of an institution can help inform research and teaching in school librarianship as well. This presentation is a follow-up to a presentation at IASL 2008 conference in Berkeley, California.
\end{abstract}

Institutional Ethnography, Middle School, Collaboration

\section{Introduction}

Much of the best-known research on school librarianship comes from outside the daily lived experiences of librarians. The research presents an idealized view of school library work, but rarely acknowledges the barriers librarians may face in putting best practices into action. Practicing school librarians tend to write about specific ways they can help students "achieve" in school, as defined by test scores and grades. These articles represent institutionally-accepted assumptions of school library work. Without looking at the invisible forces shaping the daily work of school librarianship, though, these assumptions have limited usefulness in the actual work of school librarians.

The school librarian's activities are coordinated across multiple sites. The school librarian exists at an intersection of multiple institutions, often assumed to be made up of the school building or buildings, the "institution" of school librarianship, the "institution" of librarianship, and the "institution" of teaching. These institutions shape the work of the librarian in ways both seen and unseen.

\section{Methodology and Methods}

Unseen ruling relations help shape and organize the work of the school librarian. These ruling relations can be discovered with the methods of institutional ethnography, which can explicate the power structures and ruling relations that shape the work of the school librarian. An institutional ethnography starts from the standpoint of the school librarian and works from that standpoint to examine how the work is coordinated by institutions. 


\section{The problematic: How do school librarians understand and negotiate the social organization of the institutions within which they work?}

The pervasiveness of the relations of ruling and the objectification of these structures are what makes them so difficult to make visible to people who take them for granted. Smith argues that "traditional sociology" objectifies people and their doings and precludes inquiry and discovery from within the topic (Smith, 2005). Institutional ethnography is grounded in the standpoint of the people whose experiences are being explicated and it tries to make those ruling structures visible. The method of inquiry does not turn the people whose experiences are being studied into aggregated, context-free numbers or anonymous survey quotes. "The promise of institutional ethnography is that it maintains the subjectivity of those whose experience is problematized" ((Campbell \& Gregor, 2004), p. 101).

This study uses traditional ethnographic methods of interviews, participant-observation, and data analysis. The difference between this study and other types of ethnographic studies is its focus on the organizing forces affecting the librarian.

I spent two and a half months on site as a participant-observer in a school media center in the Midwestern United States. The media center was located in a school serving students aged eleven, twelve, and thirteen. This type of school is currently known in the US as a "Middle School," teaching grades six and seven. The students are divided into groups known as teams and are assigned to the same group of teachers for their two years in this building.

The media center is staffed by a certified media specialist with a master's degree in library science and a media center aide with more than five years of experience working in school media centers. I refer to the media specialist as "Eliza," a pseudonym chosen by her. Eliza worked at an elementary school for four years before moving to the middle school at the start of the school year. She works from 7:30 to 3:20 every day, while the aide is contracted to work from 8:15 until 2:45 every day.

I use a generous notion of work in this study. "By institutional ethnographers, 'work' is used in a generous sense to extend to anything done by people that takes time and effort, that they mean to do, that is done under definite conditions and with whatever means and tools, and that they may have to think about" ((Smith, 2005), p. 151). Any work the librarian does, including the work of being a parent, friend, or partner, has the potential of shaping her work as a librarian. I will be especially interested, though, in the work the librarian specifically associates with being a school librarian or an educator. "The concept of work and work knowledge as they are conceived in institutional ethnography orients the researcher to learn from people's experiences regarding what they actually do, how their work is organized, and how they feel about it” ((Smith, 2005), p. 155).

Data collection was aimed at getting information about how the key participant and others around her understand the social organization of their work. I followed Eliza around with a notebook and pen, jotting down notes throughout the day. I used the constant comparison method to analyze the notes from the observations and determine loose categories for 
incidents and observations. I also interviewed Eliza and a reading coach and read documents they read or recommended to me, including the student handbook. Themes emerged naturally from the observations and interviews. Students were not interviewed.

An institutional ethnography does not seek generalizability of the experiences of individuals. It is not an examination of how a particular phenomenon affects specific individuals, but is an example of how the experiences of embodied individuals can explicate social organization and ruling relations. The generalizability of this study would be in showing a way of viewing library work as socially constructed. This report reflects the researcher as much as it reflects the site and the main participant.

\section{Findings}

Social organization was apparent in how students accessed the media center, how technology was managed, and how collaboration was carried out. These categories emerged from reading and analyzing notes taken during the observation periods

\section{Access}

The media center is open from 7:30 to 3:20. Students can obtain a "study hall pass" in the morning from 7:30 until 7:52. There are 12 study hall passes for each grade, meaning a total of 24 students can have access to the media center before school. With almost 900 students, there are three lunch periods, meaning that at any given time, two-thirds of the students are in class and there is no lunchtime access to the media center. The media center is open after school. Class time ends at 2:58, but the school buses leave at 3:07, meaning only students who live within walking distance of the school have after-school access.

Eliza had to negotiate for that amount of access. Faculty and staff are expected to be in the hall, conducting the flow of traffic for almost 900 students leaving classes, stopping at their lockers, and going to the buses, bike racks, or walking route. The principal had told Eliza to be stationed outside the media center during the dismissal time, which would mean she would not be able to help students in the media center. When she asked by email to be allowed to stay in the media center during that time, the principal didn't respond. Eliza decided that she would continue to stay in the media center during dismissal time unless she was directly told not to, because she felt students were entitled to have access to the media center.

During the school day, students came to the media center with their reading teachers as part of class. Each "team" of teachers had a designated day to bring their classes into the media center. Since scheduling is independently worked out by each team of teachers, based around the assigned lunch time and some electives, each day in the library followed a completely different schedule. The previous media specialist had set up the media center visit schedule to encourage more visits to the media center. Eliza explained to me in an interview that the previous media specialist had come from an elementary school library and was more comfortable with fixed scheduling. The previous media specialist also felt 
that students on fixed scheduling were more likely to return books on time. As this was Eliza's first year, she did not make any major changes in the scheduling plan.

Institutional perceptions of students as a group affected their access to the media center and the interactions between school library workers and students. The majority of students who visited the media center during the period of observation were with their reading teachers as part of a class. However, some teachers chose not to bring their students to the media center, either because they did not have time, they did not need to use the media center, or they did not believe the students were behaving appropriately. Students who did not come in to the media center as part of a class were required to prove their right to be in the media center by showing a hall pass, meaning they had to get permission from a teacher to use the media center. These rules seemed to send a message that using the media center/ library is a privilege dependent on an adult's presence or permission. Students were also required to sign in as a way of keeping track of their movements in the school building.

Many schools in the United States use "hall passes" to try to control the movement of students during class periods. These "hall passes" are intended to represent the authority of the adults in the school (Commanday, 1994). The "hall pass" system relies on school faculty and staff enforcement of the system. This can lead to individual students being greeted in the library with “where's your pass?” This expectation of enforcement can also lead to school library workers denying service to students until the students display their right to be in the media center.

These practices are presented to students as ways to ensure their "safety." At the same time, though, they act as barriers to access to the media center and the information within. The practices also act as constraints on the relationship between the library workers and the students. These institutional practices can also reduce the student to an object, a potential delinquent whose behavior is only controlled by an item representing the authority of an adult in the institution (Foucault, 1995).

\section{Technology}

Technology plays a major role in school library work in this Midwestern US middle school. The media specialist mediates between building faculty and the district information technology division. She is the only person in the building who has access to the work order database, so teachers and staff members must go to her when technology needs to be fixed. Sometimes, Eliza is able to find solutions herself or refer them to the building IT specialist, who splits his time between two schools each week.

Eliza did not get visibly frustrated with technology problems with the exception of problems with the mobile computer lab. This is a large metal cart with 25 laptop computers and one wireless access point built in. It can be rolled to any classroom and plugged into a data port so all of the students can use the Internet without leaving the classroom. However, the mobile lab consistently had problems when more than eight students would try to log on at once. The computers would slow down dramatically, as all 
of the functions rely on the student being logged in with his or her district username and password.

One morning, we attempted to help a math teacher whose students were using the mobile lab to work on computer slide show presentations. After we left the classroom, Eliza expressed frustration to me about the amount of money spent on technology that does not reliably work: "We're doing so much to try to get teachers to use technology, but there are all these barriers in place." She felt there was a simple solution: to acquire one more mobile access point to put on the lab cart so more students could log on at the same time, especially in classrooms that were not near permanent access points that had been mounted throughout the school building. She was frustrated, however, because she felt that the district information technology people did not believe there was a problem. One IT person had been a teacher at the same school the year before and stated that he had never had a problem with the lab. The system appears to privilege the view of people who are not currently in the building over those who are in the building experiencing the problem.

The media specialist also uses technology to carry out many of her daily work functions. The media center's catalog is online as part of a district federated catalog. Circulation is controlled by a computer system, bar-codes, and scanners. The district student database is in one system, while the school's catalog and circulation information is in another system. The district uses a third system to move information from the district student database to the district's circulation database. The student information is transferred automatically. While the system seems to work for most of the students' information, there are a few whose information seems to fall through the cracks. For example, the circulation record of one student changes at least once a week to indicate that she attends a different middle school in the area, although she has been attending this school for the entire school year. Another student was added to the district student database during my observation time, but her information did not transfer into the circulation database.

While these issues created small problems that were relatively easy for Eliza to fix, a bigger problem was when the system would indicate that students who had moved away with books on their records were "inactive." While it might seem logical to indicate that a student who is no longer in the district is inactive, this action creates problems. An inactive record can be eligible for deletion, leaving the information about the books in a kind of limbo. The system's deletion process also didn't take into account that students can and do move between the schools. Eliza and the aide both spoke of situations where students leave with books on their records and are deleted, only to return to the same school. The system is not designed to take into account the transience of the student population, and so can cause inventory problems.

Eliza can ameliorate some of the problems caused by the transfer or non-transfer of information as a district Super-user of the catalog database. She has a level of access that other users in the district do not have. She tries not to use that power too much, as she feels it would be unfair to media specialists in the district who do not have that power. However, becoming a Super-user appeared to be one way she could negotiate the system. 


\section{Collaboration}

During the observation period, I took part in two collaborative projects involving the media specialist and reading teachers. The planning of the collaborative work took place somewhat spontaneously, as the reading teachers were in the library with their classes. For one project, students were to create short videos about books on an upcoming book award nominee list, to encourage other students to read the books. For the other project, students were to write short reviews to be added to the school catalog. Eliza's main function on these projects appeared to be technological, providing access to catalog functions, and helping students learn how to use movie-making technology. However, she also helped refine the rubric used to rate the students. Also, because a teacher was absent one day, we helped students enter their reviews in the catalog.

While on the site, I observed several potential barriers to collaboration that rarely seem to be taken into account in published research. Two major issues were scheduling and turnover. While these issues might be touched on in research, they play a major role in the daily work life of the media specialist.

In this middle school, with 900 students divided into six teams, with three different lunch periods (since the cafeteria cannot accommodate all of the students at the same time,) each team can be on a completely different schedule. Unlike teachers on the teams, the media specialist does not have a planning period and has the possibility of having lunch with those teachers only once a week. Therefore, her opportunities for collaboration are limited to the day of the week the reading teachers bring their students to the media center. Not every teacher visits the media center each time he or she is scheduled. During some of the visits, Eliza teaches a library or information-literacy lesson. If she can get information from the teacher about what the class is working on, she ties the lesson into their work. Early in the year, she was able to meet with some teachers to decide when each team would benefit most from each lesson.

Turnover can become a major barrier to collaboration. One key to collaboration is developing a relationship with teachers, learning what they need, and even anticipating their needs. Moving disrupts those relationships. Because this was Eliza's first year in this building, she had to get to know a whole new group of teachers before collaboration could happen smoothly. At the same time, there were hints of changes to come. One of the teachers involved in the collaboration project mentioned earlier was moving to a new teaching position in the school. While this might provide new opportunities for collaboration, if the school culture promotes the idea that media center visits are for reading teachers, she might not take advantage of collaboration opportunities. Meanwhile, the two assistant principals were leaving, meaning for the next school years, teachers will have to adjust to new leadership styles and personalities. Also, the school was losing several literacy support staff members due to district budget cuts.

It takes more than being a leader in the school to facilitate collaboration. Each school's culture is different. Eliza negotiates the barriers caused by scheduling and turnover by bringing ideas to teachers while teachers are in the media center with their classes. Although she is ambivalent about fixed scheduling, the fixed scheduling instated by the 
previous media specialist gives Eliza more access to teachers than she might have otherwise. Eliza also spends time getting to know teachers and visiting with them while they are in the media center, so she can have a better understanding of their needs and teaching style. Thanks to having an aide in the library for most of the school day, she can also visit classrooms for higher visibility and problem-solving.

\section{Conclusions}

The institutional forces shaping school library work are often taken for granted. Some, such as hall passes, are justified as ways of keeping chaos out of schools. However, they affect relationships with students, teachers, and others. Scheduling decisions made because of lack of room in the cafeteria can lead to barriers to collaboration with teachers. A student database system designed to purge itself of outdated records can lead to the loss of information about the whereabouts of media center materials. A system designed to control and track students might lead to students believing that their right to access a library or media center is dependent on the permission or presence of an adult. If the school media center is where young people learn about libraries, what are media centers teaching young people about libraries? Are social relations and institutional expectations having an unexpected effect on the perception young people have of libraries?

\section{References}

Campbell, M. L., \& Gregor, F. M. (2004). Mapping social relations : a primer in doing institutional ethnography (U.S. ed.). Walnut Creek, CA: AltaMira Press.

Commanday, P. M. (1994). The hall pass. Education Digest, 59(8), 17.

Foucault, M. (1995). Discipline and punish : the birth of the prison (2nd Vintage Books ed.). New York: Vintage Books.

Smith, D. E. (2005). Institutional ethnography : a sociology for people. Walnut Creek, CA: AltaMira Press.

\section{Biographical Notes}

Jennifer Crispin is an Assistant Teaching Professor at the University of Missouri's School of Information Science and Learning Technologies. She has an MLS and is a doctoral candidate in library science.

\section{Statement of Originality}

This statement certifies that the paper above is based upon original research undertaken by the author and that the paper was conceived and written by the author(s) alone and has not been published elsewhere. All information and ideas from others are referenced. 